Published in final edited form as:

J Child Psychol Psychiatry. 2010 November ; 51(11): 1251-1259. doi:10.1111/j.

1469-7610.2010.02257.x.

\title{
Attentional networks in children and adolescents with autism spectrum disorder
}

\author{
Brandon Keehn ${ }^{1,2,3}$, Alan J. Lincoln ${ }^{4}$, Ralph-Axel Müller ${ }^{2,5}$, and Jeanne Townsend ${ }^{3,5}$ \\ 1Joint Doctoral Program in Language and Communicative Disorders, San Diego State University/ \\ University of California, San Diego, USA \\ ${ }^{2}$ Brain Development Imaging Laboratory, Department of Psychology, San Diego State University, \\ USA \\ ${ }^{3}$ Research on Aging and Development Lab, Department of Neurosciences, University of \\ California, San Diego, USA \\ ${ }^{4}$ Developmental Neuropsychology Laboratory, Alliant International University, California, USA \\ ${ }^{5}$ Department of Cognitive Science, University of California, San Diego, USA
}

\begin{abstract}
Background-Individuals diagnosed with autism spectrum disorder (ASD) exhibit lifelong abnormalities in the adaptive allocation of visual attention. The ubiquitous nature of attentional impairments in ASD has led some authors to hypothesize that atypical attentional modulation may be a factor in the development of higher-level sociocommunicative deficits.

Method-Participants were 20 children with ASD and 20 age- and Nonverbal IQ-matched typically developing (TD) children. We used the Attention Network Test (ANT) to investigate the efficiency and independence of three discrete attentional networks: alerting, orienting, and executive control. Additionally, we sought to investigate the relationship between each attentional network and measures of sociocommunicative symptom severity in children with ASD.
\end{abstract}

Results-Results indicate that the orienting, but not alerting or executive control, networks may be impaired in children with ASD. In contrast to TD children, correlational analyses suggest that the alerting and executive control networks may not function as independently in children with ASD. Additionally, an association was found between the alerting network and social impairment and between the executive control network and IQ in children with ASD.

Conclusions-The results provide further evidence of an impairment in the visuospatial orienting network in ASD and suggest that there may be greater interdependence of alerting and executive control networks in ASD. Furthermore, decreased ability to efficiently modulate levels of alertness was related to increased sociocommunicative deficits, suggesting that domain-general attentional function may be associated with ASD symptomatology.

\section{Keywords}

Autism; reaction time; visual attention; alerting; orienting; executive control

(C) 2010 Association for Child and Adolescent Mental Health.

Correspondence to: Brandon Keehn, San Diego State University, MC1863 6363 Alvarado Ct., \#225N, San Diego, CA 92120, USA; Tel: (619)-594-7350; Fax: (619)-594- 8707; bkeehn@ucsd.edu.

Conflict of interest statement: No conflicts declared. 
Individuals diagnosed with autism spectrum disorder (ASD) exhibit early (Elsabbagh et al., 2009; Osterling, Dawson, \& Munson, 2002; Swettenham et al., 1998; Zwaigenbaum et al., 2005) and pervasive (see Allen \& Courchesne, 2001; Burack, Enns, Stauder, Mottron, \& Randolph, 1997, for reviews) abnormalities in the allocation of visual attention. The ubiquitous nature of attentional impairments in ASD has led some authors to hypothesize that early atypical attentional modulation may, in part, act as a significant contributing factor in the development of higher-level sociocommunicative deficits (Belmonte \& YurgelunTodd, 2003; Dawson \& Lewy, 1989; Gold \& Gold, 1975; Ornitz, 1988; Pierce, Glad, \& Schreibman, 1997).

Recently, Posner and Fan (2004) proposed conceptualizing attention as an organ system. This system is comprised of three specialized neurofunctional networks, previously described by Posner and Petersen (1990), which are responsible for a distinct set of cognitive processes: the alerting, orienting, and executive control networks. The authors hypothesize that this conceptualization may assist in elucidating differences in attentional modulation between typically developing (TD) individuals and individuals with atypical attentional processes. Evidence from behavioral, neuropsychological, and neuroimaging investigations now support the theory of separable anatomical networks responsible for unique sets of attentional functions (see Raz \& Buhle, 2006, for a review); however, interactions between these networks are also important for successful and efficient attentional modulation in TD adults (Callejas, Lupianez, Funes,\&Tudela, 2005; Callejas, Lupianez, \& Tudela, 2004; Fan et al., 2009).

The alerting network is responsible for achieving and maintaining a state of increased sensitivity to incoming information. Alertness has been divided into tonic and phasic components (see Sturm \& Willmes, 2001, for review). Tonic alertness is a state of general wakefulness; endogenously controlled tonic alertness (referred to as vigilance or sustained attention) is the voluntary maintenance of alertness at a certain level. Phasic alertness is a more transient alert state, modulated by a warning that precedes a target stimulus. The orienting network is responsible for the selection of information from sensory input. Orienting visual attention has been defined as disengaging, shifting, and reengaging attention (Posner, Walker, Friedrich, \& Rafal, 1984). Finally, the executive control network is a multidimensional attentional system, responsible for inhibition, conflict resolution, planning, and cognitive flexibility.

Abnormal function of each attentional network has been demonstrated in ASD. Furthermore, specific deficits in alerting (Gold \& Gold, 1975; Dawson \& Lewy, 1989), orienting (Ornitz, 1988), and executive control (Ozonoff, Pennington, \& Rogers, 1991) have been hypothesized to contribute to the development of ASD. Prior research on alertness/arousal in ASD has been inconsistent; individuals with ASD exhibit intact endogenous tonic (Garretson, Fein, \& Waterhouse, 1990; Pascualvaca, Fantie, Papageorgiou, \& Mirsky, 1998) and phasic (Raymaekers, van der Meere, \& Roeyers, 2006) components of alerting, yet also demonstrate atypical arousal (e.g., Anderson \& Colombo, 2009; Hirstein, Iversen, \& Ramachandran, 2001) and reduced sensitivity to novel information (e.g., Ciesielski, Courchesne, \& Elmasian, 1990; Keehn \& Joseph, 2008).

Dysfunctional shifting and disengagement of attention has also been reported in ASD. Dawson and colleagues (1998) demonstrated that children with ASD have difficulties orienting to both social and non-social information within their environment. Previous studies using the Posner cueing paradigm (1980) have shown that individuals with ASD have difficulties disengaging (Wainwright- Sharp \& Bryson, 1993) and shifting visual attention (Townsend et al., 1999; Townsend, Harris, \& Courchesne, 1996), and demonstrate atypical activation of the orienting network (Haist, Adamo, Westerfield, Courchesne, \& 
Townsend, 2005). Furthermore, studies employing the gap-overlap paradigm, a task used to evaluate attentional disengagement by examining the response time (RT) differences to targets appearing with and without a central fixation, have also demonstrated that children with ASD evidence significant impairments in disengaging visual attention (Elsabbagh et al., 2009; Landry \& Bryson, 2004).

Finally, the extant literature on executive control abilities in ASD suggests intact inhibitory processing (Lopez, Lincoln, Ozonoff, \& Lai, 2005; Ozonoff \& Strayer, 1997), but impaired cognitive flexibility (Courchesne et al., 1994; Ozonoff, Strayer, McMahon, \& Filloux, 1994). Additionally, there appears to be a relationship between IQ and executive abilities in individuals with ASD (Liss et al., 2001; Lopez et al., 2005).

Together, these findings indicate that individuals with ASD exhibit impairments in each attentional network; however, no study has attempted to examine each attentional network in the same cohort of children. The Attention Network Test (ANT; Fan et al., 2002), which consists of both a cued reaction time task (Posner, 1980) and a flanker paradigm (Eriksen \& Eriksen, 1974), permits investigators to examine each attentional network in the context of a single integrated task. The test, which was designed to be short and simple, has been used in TD children and adults (Fan et al., 2002; Rueda et al., 2004), as well as clinical populations with attentional abnormalities (for example, see Johnson et al., 2008; Urbanek et al., 2009). To date, no study has employed the ANT to investigate attention networks in ASD. Our goal in the current study was to use the ANT to simultaneously examine alerting, orienting, and executive control networks in children and adolescents with ASD. Moreover, because it has been suggested that abnormalities in the modulation of attention may be related to sociocommunicative deficits, we sought to examine the relationship between attentional function and sociocommunicative impairments in children with ASD.

\section{Methods}

\section{Participants}

Twenty children and adolescents with ASD (19 males), all of whom met DSM-IV-TR (APA, 2000) criteria for an ASD (autistic disorder = 9; Asperger's disorder $=11$ ), and an age- and nonverbal IQ-matched comparison group of 20 typically developing (TD) children and adolescents (19 males) were included in the present study. Clinical diagnoses were confirmed using the Autism Diagnostic Interview - Revised (ADI-R; Rutter, Le Couteur, \& Lord, 2003), the Autism Diagnostic Observation Schedule (ADOS; Lord, Rutter, DiLavore, \& Risi, 1999), and expert clinical judgment (author AJL). Children with ASD-related medical conditions (e.g., Fragile-X syndrome, tuberous sclerosis) were excluded.

Per parent-report, participants in the TD group had no family history of ASD and were free of ASD-related symptoms or any other neurological or psychiatric conditions. Independentsamples $t$-tests confirmed that groups were matched on age, $t(38)=0.4, p=.72$, and nonverbal IQ, $t(38)=-.7, p=.49$, as determined by the Wechsler Abbreviated Scale of Intelligence (WASI; Wechsler, 1999; see Table 1). Informed consent was obtained from all participants in accordance with the University of California, San Diego and San Diego State University Institutional Review Boards.

\section{Apparatus}

The experiment was presented using Presentation software (nbs.neuro-bs.com) on a 1.83 GHz/1GB PC with a 19-inch CRT monitor. Participants were seated approximately $57 \mathrm{~cm}$ from the monitor. Responses were recorded with a Cedrus (Model RB-420) button-box device. 


\section{Stimuli}

Stimuli consisted of a central target, an arrow pointing left or right, flanked on each side by bars without arrowheads (neutral condition) or arrows either pointing in the same direction (congruent condition) or the opposite direction (incongruent condition) (see Figure 1a). Stimuli were black and displayed on a gray background. Each arrow subtended a visual angle of $0.6^{\circ} \times 0.25^{\circ}$ and was separated from neighboring arrows by $0.1^{\circ}$. The entire row of stimuli thus subtended a visual angle of $3.4^{\circ}$. The cue was an asterisk subtending $0.41^{\circ} \times$ $0.41^{\circ}$ visual angle, and appeared directly over fixation cross (center cue), $1.2^{\circ}$ above and below the fixation cross (double cue), or $1.2^{\circ}$ above or below fixation cross (spatial cue) (see Figure 1b).

\section{Design}

The experiment consisted of 288 trials, divided into three blocks of 96 trials. Within each block, cue (no cue, center, double, spatial [all valid]), and flanker (neutral, congruent, incongruent) were varied in pseudorandom order.

\section{Procedure}

The participants' task was to indicate whether the center arrow pointed left or right via a button box response using the index and middle fingers of their dominant hand. Each trial lasted $4000 \mathrm{~ms}$ and began with a fixation cross presented alone for a variable duration (400$1600 \mathrm{~ms}$ ). With the fixation cross remaining on the screen, a cue (no cue, center, double, spatial [all valid]) appeared for $100 \mathrm{~ms}$. Following the cue there was a fixation period (fixation cross presented alone) for $400 \mathrm{~ms}$. Subsequent to the fixation period, the target and flankers appeared above or below the fixation cross and remained on the screen until the participant responded or $1700 \mathrm{~ms}$ had elapsed. A post-target fixation period then appeared for a duration equal to $3500 \mathrm{~ms}$ minus the duration of the initial fixation and RT (see Figure 1c). Twenty-four practice trials were administered with feedback before the start of the experimental trials.

Prior to beginning the experiment participants were told they were going to play the 'stars and arrows' game. They were instructed to press the left button if the middle arrow pointed left or the right button if the middle arrow pointed right, regardless of which stimuli appeared next to the center arrow (congruent, incongruent, neutral). Participants were told that sometimes stars would appear to tell them when or when and where the arrows would appear. Stars in the center or above and below- were explained as cues to inform participants when the arrows would appear, whereas stars above or below were explained as cues to inform participants when and where the arrows would appear. Finally, participants were told to respond as quickly as possible without making errors.

\section{Results Error}

Mean error rates were entered into a mixed-model repeated measures ANOVA with between-subject factor group (ASD, TD) and within-subject factors cue (no, center, double, spatial) and flanker (neutral, congruent, incongruent). As shown in Figure 2, there were main effects of cue, $F(3,114)=4.7, p<.01, \eta_{\mathrm{p}}{ }^{2}=.11$, and flanker, $F(2,76)=12.1, p<.01$, $\eta_{\mathrm{p}}{ }^{2}=.24$. Importantly, there was no difference for the mean error rate between the ASD (3\%) and TD (3\%) groups, nor were there any significant interactions between group and any factor $(p s>.3)$. 


\section{Response time}

Median response times (RT) for correct trials were entered into mixed-model repeated measures ANOVA with between-subject factor group (ASD, TD) and within-subject cue (no, center, double, spatial) and flanker (neutral, congruent, incongruent). As illustrated by Figure 2, there was a main effect of cue, $F(3,114)=114.5, p<.01, \eta_{\mathrm{p}}{ }^{2}=.75$, reflecting accelerated RT to spatial cues compared to no, center, and double cue conditions and faster RT to center and double cue compared to the no cue condition. In addition, there was a main effect of flanker, $F(2,76)=194.5, p<.01, \eta_{\mathrm{p}}^{2}=.84$, reflecting faster RT to neutral and congruent flankers compared to incongruent flankers. There was also an interaction between cue and flanker, $F(6,228)=8.7, p<.01, \eta_{\mathrm{p} 2}=.19$. These main effects and interaction were expected based on previous ANT findings (Fan et al., 2002).

There was no significant RT difference between groups, $F(2,38)=1.9, p>.1, \eta_{\mathrm{p} 2}=.05$; however, there were marginally significant interactions of group and cue, $F(3,114)=2.5, p$ $<.07, \eta_{\mathrm{p}}{ }^{2}=.06$, and of group and flanker, $F(2,76)=2.7, p<.08, \eta_{\mathrm{p}}{ }^{2}=.07$.

Alerting, orienting, and executive control scores were calculated as follows. The alerting score was calculated by subtracting median RT in the double cue condition from the no cue condition (collapsed across flanker conditions). The orienting score was calculated by subtracting median RT in the spatial cue condition from the center cue condition (collapsed across flanker conditions). Finally, the executive control score was calculated by subtracting median RT in the congruent flanker condition from the incongruent flanker condition (collapsed across cue conditions). As can been seen in Figure 3, there was no significant difference between groups for alerting (ASD: 42ms; TD: 44ms), $F(1,38)=.02, p>.8, \eta_{\mathrm{p}}{ }^{2}$ $=.00$; however, orienting scores were significantly reduced in the ASD (M: $39 \mathrm{~ms})$ as compared to the TD (M: 66ms) group, $F(1,38)=8.5, p<.01, \eta_{\mathrm{p}}{ }^{2}=.18$, indicative of more inefficient orienting in the ASD relative to TD children. The executive control score was greater in the ASD (M: 122ms) compared to the TD (M: 96ms) group; however, this was not significant, $F(1,38)=3.2, p<.1, \eta_{\mathrm{p}}{ }^{2}=.08$. These results remained the same when network scores were scaled to median RT for all cue conditions and when participants with below average IQ $(<85)$ were removed. Although ANT studies commonly analyze difference scores, there has been some criticism of this method. Therefore we conducted comparable analyses using the median RTs in ANOVAs for each network to examine interactions between group and cue condition (alerting, orienting) or flanker condition (executive control). Results from these analyses support those from the difference score analyses. The interaction between group and cue was significant for the orienting score, $F(1$, $38)=8.5, p<.01, \eta_{\mathrm{p}}{ }^{2}=.18$, but not the alerting score, $F(1,38)=.2, p>.8, \eta_{\mathrm{p}}{ }^{2}=.00$, and the executive control score, $F(1,38)=3.2, p=.08, \eta_{\mathrm{p}}{ }^{2}=.08$.

\section{Network score correlational analyses}

Correlational analyses of attentional network scores were used to investigate the relationship between each network and 1) IQ, to determine if network efficiency is related to cognitive ability, 2) other attentional networks scores, to explore the independence of attentional networks, and 3) measures of ASD symptomatology, to examine the relationship between sociocommunicative impairment and network efficiency.

IQ-Correlational analyses revealed that for the ASD group neither the alerting nor the orienting score was related to verbal, nonverbal, or full scale IQ, all $p s>.1$. However, the executive control score was inversely related to verbal, $r(18)=-.67, p<.01$, nonverbal, $r(18)=-.65, p<.01$, and full scale IQ, $r(18)=-.71, p<.01$, demonstrating that lower IQs were associated with more inefficient executive control in children with ASD. Because the significant correlations in the ASD group could partially be due to greater IQ variability in 
this group, correlations were completed excluding all individuals with below average verbal and nonverbal IQ (as above). Correlation for the ASD group between executive control score and full scale IQ, $r(16)=-.5, p<.05$, remained significant, although weaker, with these individuals removed.

For the TD group, there was no relationship between any attention network score and any IQ measure, all $p s>.1$.

Attentional networks-Correlational analyses between attention network scores in prior studies have demonstrated non-significant relationships between the three attentional networks in both children and adults (Fan et al., 2002; Rueda et al., 2004). Consistent with prior research, TD children in the current study showed no correlation between the alerting, orienting, and executive control networks, all $p s>.6$. However, in children with ASD, partial correlations controlling for IQ revealed a positive relationship between the alerting and executive control networks, $r(17)=.47, p<.05$, suggesting that these two networks may not function as independently in children with ASD. A between-group comparison of the magnitude of the alerting-executive control correlations revealed that the relationship between these networks was significantly greater in the ASD as compared to the TD group, $\mathrm{Z}_{\mathrm{rASD}-\mathrm{rTD}}=1.69, p<.05$, one-tailed.

ASD symptom severity-The relationship between the efficiency of each attentional network and sociocommunicative impairment was assessed by correlating attentional network scores with algorithm scores from the Autism Diagnostic Observation Schedule (ADOS; Lord et al., 1999). ADOS algorithm scores are comprised of quantitative observational ratings of communication and social behaviors that are acquired during a set of experimenter- administered social situations. Higher scores on the ADOS represent increased levels of ASD symptomatology. Partial correlations controlling for IQ between ADOS algorithm scores and attention network scores revealed a significant association between the alerting score and the Social domain score, $r(16)=.50, p<.05$. There were no other significant correlations between attention network scores and ADOS domain scores (see Table 2).

\section{Discussion}

The aim of the present study was twofold. Our first goal was to investigate the efficiency and independence of the alerting, orienting, and executive attentional networks in children and adolescents with ASD. Children and adolescents demonstrated decreased efficiency of the orienting, but not the alerting or executive control, network compared to their TD peers. Additionally, in contrast to TD participants in the current and previous studies, the ASD group evidenced increased interdependence between the alerting and executive control networks. Second, based on previous hypotheses that attentional impairments may be related to ASD symptomatology we examined the relationship between the efficiency of each network and measures of sociocommunicative impairment in ASD. Correlations between attention network scores and ADOS scores revealed that decreased alerting efficiency was associated with greater ASD sociocommunicative impairment. Each of these findings will be discussed in turn.

Consistent with previous behavioral (Townsend et al., 1999, 1996), electrophysiological (Townsend et al., 2001), and functional magnetic resonance imaging (fMRI) studies of orienting in ASD (Haist et al., 2005), we found that children with ASD exhibited impairments in orienting visual attention to non-social peripheral cues. The lower orienting score in the ASD as compared to the TD group suggests that the children with ASD benefited less from the information provided by the spatial cue relative to the central cue. 
Since the ANT does not include invalidly cued trials, task-related demands on disengagement are limited. Therefore, the finding of reduced orienting scores may indicate that children with ASD may have a slowed or impaired ability to shift visual attention towards cued locations. Adaptive allocation of visual attention and the ability to shift attention between individuals and objects within the environment may be crucial for cognitive development across many domains. Prior studies have demonstrated that children with ASD demonstrate fewer attentional shifts compared to TD and developmentally delayed children (Swettenham et al., 1998) and fail to orient to both social and non-social environmental stimuli (Dawson et al., 1998). These early orienting deficits could reflect an initial pathological process (Mundy \& Crowson, 1997), which has important downstream consequences for joint attention abilities (Dawson et al., 2004) and later developing sociocommunicative skills.

Children with ASD did not differ from TD children in the efficiency of the alerting network. The alerting score is a product of both intrinsic and phasic alertness. Intrinsic alertness is measured as the increase of RT to the no cue condition; phasic alertness is measured as the decrease of RT to double cue condition (Posner, 2008). Developmentally, greater alerting scores in TD children relative to adults reflect slower RT in the no cue condition, and, thus less efficient modulation of intrinsic alertness (Rueda et al., 2004). Our finding of equivocal alerting scores is consistent with prior findings of intact tonic (Garretson et al., 1990; Pascualvaca et al,, 1998) and phasic (Raymaekers et al., 2006) alertness. However, equivalent alerting efficiency may reflect a compensatory executive processing mechanism utilized by children with ASD (discussed below).

Additionally, while children and adolescents with ASD did not exhibit differences in efficiency of the executive control network compared to TD children, the efficiency of this network was related to IQ in the ASD but not the TD group. These findings are in agreement with previous studies, which have shown that inhibitory control is not impaired in ASD (Ozonoff \& Strayer, 1997) and that executive function abilities in individuals with ASD are related to IQ (Liss et al., 2001).

Posner and Petersen's (1990) model of attentional networks and subsequent neuroimaging studies using the ANT (Fan, McCandliss, Fossella, Flombaum, \& Posner, 2005) have demonstrated that an intrinsic network of brain areas is responsible for the modulation of each attentional network. Although the functions of these attentional networks are separable and relatively independent (Fan et al., 2002; Rueda et al., 2004), a significant interaction between cue and flanker conditions in the present study and in prior studies suggests that these networks do interact. Similar to prior studies, our TD group exhibited no significant correlations between attention network scores; however, the ASD group demonstrated a significant association between alerting and executive control networks. That is, in the ASD group, more inefficient executive control (i.e., greater interference associated with incongruent flankers resulting in a higher executive network score) was related to more inefficient alerting (i.e., increased cost of no cue relative to double cue condition resulting in an increased alerting score). The association between the alerting and executive control networks could represent compensatory processing in ASD. Children with ASD who have more intact and efficient executive control abilities may be able to more efficiently regulate levels of arousal, resulting in a greater interdependence between these networks. Alternatively, as a consequence of the dysregulation of arousal, which generates states of both hyper- and hypoarousal (e.g., Anderson \& Colombo, 2009; Hirstein et al., 2001), individuals with ASD may recruit or rely on executive control mechanisms in order to regulate atypical arousal levels. As a result, the networks modulating alertness and executive control may become more interdependent in ASD. Although speculative, one possibility is that this increased interdependence could result in reduced cognitive resources during 
periods when atypical arousal regulation is necessary, and may explain poorer response inhibition in states of high arousal in ASD (Raymaekers, van der Meere, \& Roeyers, 2004).

Because previous authors have hypothesized a link between attentional dysfunction and sociocommunicative impairment in ASD, we examined the relationship between attention network scores and measures of sociocommunicative impairment in our ASD sample. The results of these correlations suggest that decreased efficiency of the alerting network is related to increased social impairment in children with ASD. Inefficient modulation of tonic alertness may correspond to dysfunctional attentional regulation characteristic of ASD. Individuals with ASD can be both hyper-focused and easily distracted. Greater sociocommunicative difficulties may result from poorer modulation of attention given the dynamic nature of social interactions. Although corollary, the results of the current study support previous theories that hypothesize that atypical alertness/arousal may be associated with the development of sociocommunicative impairments in ASD.

A potential concern regarding the present study is the wide range in participant age. Although the current study includes individuals aged 8 to 19 years, a previous ANT study examining the developmental changes of each network (Rueda et al., 2004) demonstrated little change in orienting scores from 6-year-old children to adults. The lack of age-related changes for the orienting score has been attributed to the absence of invalid cues, as discussed above, which reduces demands for attentional disengagement. An additional concern is related to the heterogeneity of IQ scores, specifically within the ASD group. To confirm that group-related differences did not result from inclusion of lowerfunctioning individuals, participants with below average IQ were removed; between-group differences for orienting scores remained unchanged. Lastly, although the ANT is now a widely used measure, the use of subtraction scores may make the interpretation of between-group differences in the efficiency of networks difficult (Posner, 2008). However, our analyses using raw scores instead of difference scores produced exactly the same results.

Future application of the child ANT (Rueda et al., 2004) with younger children or lowerfunctioning individuals with ASD may be able to provide more detailed information about the developmental differences of attention. Recently, Posner and Rothbart (2005) have suggested that early attentional interventions may be useful tool promoting cognitive and social development. Because children with ASD evidence early attentional impairment, attentional interventions targeted at atypical attentional networks may produce generalized improvement across multiple domains.

In summary, the current study has demonstrated inefficient modulation of the orienting network in children with ASD. In addition, while the TD group demonstrated relatively independent attentional networks, we found a relationship between alerting and executive control in children with ASD, suggesting that these networks may not function as independently in ASD. Finally, inefficiency of the alerting network was associated with greater social impairment in children with ASD. Although alerting efficiency was not universally impaired in individuals with ASD, this finding indicates that withingroup differences in domain-general attentional function may be related to individual variability of sociocommunicative function along the autism spectrum.

\section{Acknowledgments}

Supported by the NIH R01-DC006155 (RAM), RO1- NS42639 (JT), P50 NS022343 (JT), and NIDCD 1T32 DC007361 (BK). Special thanks to the children and families who generously participated. 


\section{References}

Allen G, Courchesne E. Attention function and dysfunction in autism. Frontiers in Bioscience. 2001; 6:D105- 119. [PubMed: 11171544]

American Psychiatric Association (APA). Diagnostic and statistical manual of mental disorders: Text revision DSM-IV-TR. 4. Washington, DC: American Psychiatric Association; 2000.

Anderson CJ, Colombo J. Larger tonic pupil size in young children with autism spectrum disorder. Developmental Psychobiology. 2009; 51:207-211. [PubMed: 18988196]

Belmonte MK, Yurgelun-Todd DA. Functional anatomy of impaired selective attention and compensatory processing in autism. Brain Research. 2003; 17:651-664. [PubMed: 14561452]

Burack, JA.; Enns, JT.; Stauder, JEA.; Mottron, L.; Randolph, B. Attention and autism: Behavioral and electrophysiological evidence. In: Cohen, DJ.; Volkmar, FR., editors. Handbook of autism and pervasive developmental disorders. 2. New York: John Wiley \& Sons; 1997. p. 226-247.

Callejas A, Lupianez J, Funes MJ, Tudela P. Modulations among the alerting, orienting and executive control networks. Experimental Brain Research. 2005; 167:27-37.

Callejas A, Lupianez J, Tudela P. The three attentional networks: On their independence and interactions. Brain and Cognition. 2004; 54:225-227. [PubMed: 15050779]

Ciesielski KT, Courchesne E, Elmasian R. Effects of focused selective attention tasks on eventrelated potentials in autistic and normal individuals. Electroencephalography and Clinical Neurophysiology. 1990; 75:207-220. [PubMed: 1689644]

Courchesne E, Townsend J, Akshoomoff NA, Saitoh O, Yeung-Courchesne R, Lincoln AJ, James HE, Haas RH, Schreibman L, Lau L. Impair- ment in shifting attention in autistic and cerebellar patients. Behavioral Neuroscience. 1994; 108:848-865. [PubMed: 7826509]

Dawson, G.; Lewy, A. Arousal, attention, and the socioemotional impairments of individuals with autism. In: Dawson, G., editor. Autism: Nature, diagnosis, and treatment. New York: Guilford Press; 1989. p. 49-74.

Dawson G, Meltzoff AN, Osterling J, Rinaldi J, Brown E. Children with autism fail to orient to naturally occurring social stimuli. Journal of Autism and Developmental Disorders. 1998; 28:479_ 485. [PubMed: 9932234]

Dawson G, Toth K, Abbott R, Osterling J, Munson J, Estes A, Liaw J. Early social attention impairments in autism: Social orienting, joint attention, and attention to distress. Developmental Psychology. 2004; 40:271-283. [PubMed: 14979766]

Elsabbagh M, Volein A, Holmboe K, Tucker L, Csibra G, Baron-Cohen S, Bolton P, Charman T, Baird G, Johnson MH. Visual orienting in the early broader autism phenotype: Disengagement and facilitation. Journal of Child Psychology and Psychiatry. 2009; 50:637-642. [PubMed: 19298466]

Eriksen BA, Eriksen CW. Effects of noise letter upon the identification of a target letter in a nonsearch task. Perception and Psychophysics. 1974; 16:143-149.

Fan J, Gu X, Guise KG, Liu X, Fossella J, Wang H, et al. Testing the behavioral interaction and integration of attentional networks. Brain and Cognition. 2009; 70:209-220. [PubMed: 19269079]

Fan J, McCandliss BD, Fossella J, Flombaum JI, Posner MI. The activation of attentional networks. Neuroimage. 2005; 26:471-479. [PubMed: 15907304]

Fan J, McCandliss BD, Sommer T, Raz A, Posner MI. Testing the efficiency and independence of attentional networks. Journal of Cognitive Neuroscience. 2002; 14:340-347. [PubMed: 11970796]

Garretson HB, Fein D, Waterhouse L. Sustained attention in children with autism. Journal of Autism and Developmental Disorders. 1990; 20:101-114. [PubMed: 2324050]

Gold MS, Gold JR. Autism and attention: Theoretical considerations and a pilot study using set reaction time. Child Psychiatry and Human Development. 1975; 6:68-80. [PubMed: 1192887]

Haist F, Adamo M, Westerfield M, Courchesne E, Townsend J. The functional neuroanatomy of spatial attention in autism spectrum disorder. Developmental Neuropsychology. 2005; 27:425458. [PubMed: 15843105]

Hirstein W, Iversen P, Ramachandran VS. Autonomic responses of autistic children to people and objects. Proceedings of the Royal Society of London, B. 2001; 268:1883-1888.

Johnson KA, Robertson IH, Barry E, Mulligan A, Daibhis A, Daly M, Watchorn A, Gill M, Bellgrove MA. Impaired conflict resolution and alerting in children with ADHD: Evidence from the 
Attention Network Task (ANT). Journal of Child Psychology and Psychiatry. 2008; 49:1339_ 1347. [PubMed: 19120713]

Keehn B, Joseph RM. Impaired prioritization of novel onset stimuli in autism spectrum disorder. Journal of Child Psychology and Psychiatry. 2008; 49:1296- 1303. [PubMed: 19120708]

Landry R, Bryson SE. Impaired disengagement of attention in young children with autism. Journal of Child Psychology and Psychiatry. 2004; 45:1115-1122. [PubMed: 15257668]

Liss M, Fein D, Allen D, Dunn M, Feinstein C, Morris R, Waterhouse L, Rapin I. Executive functioning in high-functioning children with autism. Journal of Child Psychology and Psychiatry. 2001; 42:261- 270. [PubMed: 11280422]

Lopez BR, Lincoln AJ, Ozonoff S, Lai Z. Examining the relationship between executive functions and restricted, repetitive symptoms of autistic disorder. Journal of Autism and Developmental Disorders. 2005; 35:445-460. [PubMed: 16134030]

Lord, C.; Rutter, M.; DiLavore, PC.; Risi, S. Autism Diagnostic Observation Schedule - WPS (ADOSWPS). Los Angeles, CA: Western Psychological Services; 1999.

Mundy P, Crowson M. Joint attention and early social communication: Implications for research on intervention with autism. Journal of Autism and Developmental Disorders. 1997; 27:653-676. [PubMed: 9455727]

Ornitz EM. Autism: A disorder of directed attention. Brain Dysfunction. 1988; 1:309-322.

Osterling JA, Dawson G, Munson JA. Early recognition of 1-year-old infants with autism spectrum disorder versus mental retardation. Developmental Psychopathology. 2002; 14:239-251.

Ozonoff S, Pennington BF, Rogers SJ. Executive function deficits in high-functioning autistic individuals: Relationship to theory of mind. Journal of Child Psychology and Psychiatry. 1991; 32:1081-1105. [PubMed: 1787138]

Ozonoff S, Strayer DL. Inhibitory function in nonretarded children with autism. Journal of Autism and Developmental Disorders. 1997; 27:59-77. [PubMed: 9018582]

Ozonoff S, Strayer DL, McMahon WM, Filloux F. Executive function abilities in autism and Tourette syndrome: An information processing approach. Journal of Child Psychology and Psychiatry. 1994; 35:1015- 1032. [PubMed: 7995842]

Pascualvaca DM, Fantie BD, Papageorgiou M, Mirsky AF. Attentional capacities in children with autism: Is there a general deficit in shifting focus? Journal of Autism and Developmental Disorders. 1998; 28:467-478. [PubMed: 9932233]

Pierce K, Glad KS, Schreibman L. Social perception in children with autism: An attentional deficit? Journal of Autism and Developmental Disorders. 1997; 27:265-282. [PubMed: 9229258]

Posner MI. Orienting of attention. Quarterly Journal of Experimental Psychology. 1980; 32:3-25. [PubMed: 7367577]

Posner MI. Measuring alertness. Annals of the New York Academy of Sciences. 2008; 1129:193-199. [PubMed: 18591480]

Posner, MI.; Fan, J. Attention as an organ system. In: Pomerantz, JR.; Crair, MC., editors. Topics in integrative neuroscience: From cells to cognition. Cambridge: Cambridge University Press; 2004.

Posner MI, Petersen SE. The attention system of the human brain. Annual Review of Neuroscience. $1990 ; 13: 25-42$.

Posner MI, Rothbart MK. Influencing brain networks: Implications for education. Trends in Cognitive Sciences. 2005; 9:99-103. [PubMed: 15737817]

Posner MI, Walker JA, Friedrich FJ, Rafal RD. Effects of parietal injury on covert orienting of attention. Journal of Neuroscience. 1984; 4:1863-1874. [PubMed: 6737043]

Raymaekers R, van der Meere J, Roeyers H. Event-rate manipulation and its effect on arousal modulation and response inhibition in adults with high functioning autism. Journal of Clinical and Experimental Neuropsychology. 2004; 26:74-82. [PubMed: 14972695]

Raymaekers R, van der Meere J, Roeyers H. Response inhibition and immediate arousal in children with high-functioning autism. Child Neuropsychology. 2006; 12:349-359. [PubMed: 16911978]

Raz A, Buhle J. Typologies of attentional networks. Nature Review Neuroscience. 2006; 7:367-379.

Rueda MR, Fan J, McCandliss BD, Halparin JD, Gruber DB, Lercari LP, Posner MI. Development of attentional networks in childhood. Neuropsychologia. 2004; 42:1029-1040. [PubMed: 15093142] 
Rutter, M.; Le Couteur, A.; Lord, C. Autism Diagnostic Interview - Revised. Los Angeles, CA: Western Psychological Services; 2003.

Sturm W, Willmes K. On the functional neuroanatomy of intrinsic and phasic alertness. Neuroimage. 2001; 14(1 Pt 2):S76-84. [PubMed: 11373136]

Swettenham J, Baron-Cohen S, Charman T, Cox A, Baird G, Drew A, Rees L, Wheelwright S. The frequency and distribution of spontaneous attention shifts between social and nonsocial stimuli in autistic, typically developing, and nonautistic developmentally delayed infants. Journal of Child Psychology and Psychiatry. 1998; 39:747-753. [PubMed: 9690937]

Townsend J, Courchesne E, Covington J, Westerfield M, Harris NS, Lyden P, Lowry TP, Press GA. Spatial attention deficits in patients with acquired or developmental cerebellar abnormality. Journal of Neuroscience. 1999; 19:5632-5643. [PubMed: 10377369]

Townsend J, Harris NS, Courchesne E. Visual attention abnormalities in autism: Delayed orienting to location. Journal of the International Neuropsychology Society. 1996; 2:541-550.

Townsend J, Westerfield M, Leaver E, Makeig S, Jung T, Pierce K, Courchesne E. Eventrelated brain response abnormalities in autism: Evidence for impaired cerebello-frontal spatial attention networks. Brain Research. 2001; 11:127-145. [PubMed: 11240116]

Urbanek C, Neuhaus AH, Opgen-Rhein C, Strathmann S, Wieseke N, Schaub R, Hahn E, Dettling M. Attention network test (ANT) reveals genderspecific alterations of executive function in schizophrenia. Psychiatry Research. 2009; 168:102-109. [PubMed: 19464736]

Wainwright-Sharp JA, Bryson SE. Visual orienting deficits in high-functioning people with autism. Journal of Autism and Developmental Disorders. 1993; 23:1-13. [PubMed: 8463191]

Wechsler, D. Wechsler's Abbreviated Scale of Intelligence. San Antonio, TX: The Psychological Corporation; 1999.

Zwaigenbaum L, Bryson S, Rogers T, Roberts W, Brian J, Szatmari P. Behavioral manifestations of autism in the first year of life. International Journal of Developmental Neuroscience. 2005;

23:143-152. [PubMed: 15749241] 
Key points

- Individuals with autism spectrum disorder (ASD) exhibit widespread attentional impairments.

- We investigated the efficiency of the alerting, orienting, and executive control networks in ASD and found that children with ASD demonstrate a more inefficient orienting network.

- Unlike typically developing children, children with ASD evidenced significant interdependence between alerting and executive control networks, suggesting diminished executive modulation of arousal.

- Additionally, increased inefficiency of the alerting network was related to greater social impairment in children with ASD.

- Domain-general impairment in modulating alertness in children with ASD was related to domain-specific clinical impairments in reciprocal social interaction. 


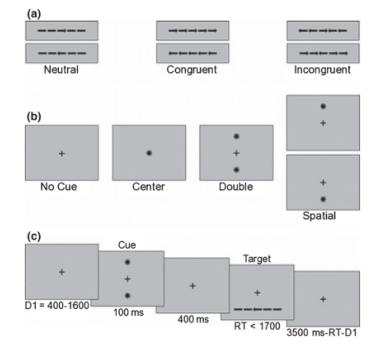

Figure 1.

Illustration of attention network test. Examples of flanker types (a), cue types (b), and the sequence and timing of a single trial (double cue neutral flanker condition displayed) (c) 


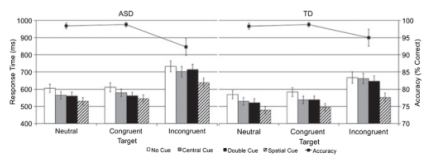

Figure 2.

Bar graphs correspond to median response time (left axis) for correct trials only as a function of group, flanker, and cue. Line graphs correspond to average accuracy rates (right axis) as a function group and flanker (collapsed across cue). Error bars represent one standard error of the mean 

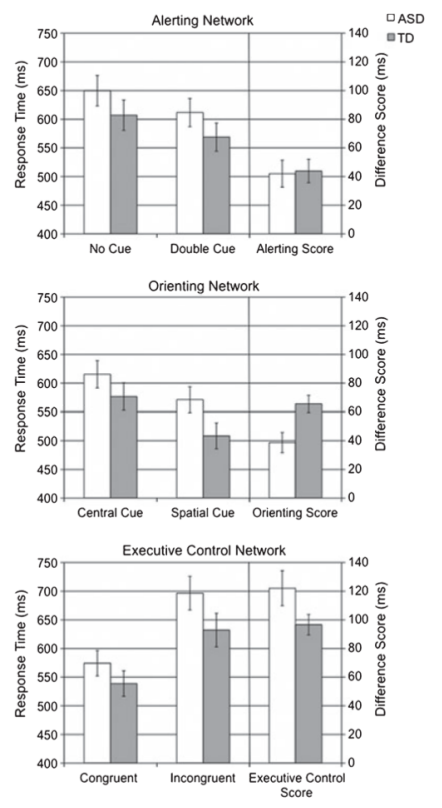

Figure 3.

Attention network scores (right axis) and collapsed median response time for relevant cue or flanker conditions (left axis). Error bars represent one standard error of the mean 
Table 1

Participant characteristics

\begin{tabular}{lcc}
\hline & ASD $(\mathbf{n}=\mathbf{2 0}) \mathbf{M}(\mathbf{S D})$ Range & TD $(\mathbf{n}=\mathbf{2 0}) \mathbf{M}(\mathbf{S D})$ Range \\
\hline Age & $13 ; 9(3 ; 1)$ & $13 ; 5(2 ; 10)$ \\
& $8 ; 8-19 ; 11$ & $8 ; 11-18 ; 10$ \\
Verbal IQ & $108(18)$ & $111(10)$ \\
& $80-147$ & $87-134$ \\
Nonverbal IQ & $111(15)$ & $113(10)$ \\
& $76-140$ & $96-132$ \\
\hline
\end{tabular}


Table 2

Correlations between attention networks and Autism Diagnostic Observation Schedule algorithm scores

\begin{tabular}{lcccc}
\hline & Communication & Social & Total & Repetitive behaviors \\
\hline Alerting & .04 &. $.50^{*}$ & .39 & -.07 \\
Orienting & .10 & -.22 & -.13 & .14 \\
Executive control & .30 & .28 & .34 & $-\mathrm{s} .19$ \\
\hline$*$ & & & & \\
$p<.05$. & & & &
\end{tabular}

